\title{
Oridonin Attenuates the Effects of Chronic Alcohol Consumption Inducing Oxidative, Glycative and Inflammatory Injury in the Mouse Liver
}

\author{
SHENG-LEI YAN ${ }^{1 \#}$, CHIN-SHIU HUANG ${ }^{2 \#}$, MEI-CHIN MONG $^{2}$ and MEI-CHIN YIN ${ }^{2,3}$ \\ ${ }^{1}$ Department of Internal Medicine, Chang Bing Show-Chwan Memorial Hospital, Lukang, Taiwan, R.O.C.; \\ ${ }^{2}$ Department of Food Nutrition and Health Biotechnology, Asia University, Taichung, Taiwan, R.O.C.; \\ ${ }^{3}$ Department of Medical Research, China Medical University Hospital, \\ China Medical University, Taichung, Taiwan, R.O.C.
}

\begin{abstract}
Background/Aim: Oridonin (Ori) is a diterpenoid naturally present in medicinal plants with a potential as an antioxidant agent. This study aimed to evaluate the hepatic antioxidative, anti-glycative and anti-inflammatory properties of Ori at 0.125 and $0.25 \%$ against chronic ethanol intake in mice. Materials and Methods: Mice were divided into five groups: i) normal diet group, ii) Ori group, iii) ethanol diet (LieberDeCarli liquid diet with ethanol) group, iv) ethanol diet plus $0.125 \%$ Ori and v) ethanol diet plus $0.25 \%$ Ori. After 8 weeks of Ori supplementation, blood and liver tissue were used for analyses. Results: Ethanol increased the production of reactive oxygen species and nitric oxide, decreased glutathione content, and lowered the activity of glutathione peroxide, glutathione reductase and catalase. Ethanol suppressed the hepatic $m R N A$ expression of nuclear factor E2-related factor 2. Ori supplements reversed these changes. Ethanol increased hepatic $N^{e}$-(carboxyethymethyl)-lysine (CML) and pentosidine levels, and enhanced aldose reductase (AR) activity and $m R N A$ expression. Ori supplements at only $0.25 \%$ decreased CML and pentosidine levels, and lowered the AR activity as well as its $m R N A$ expression. Ethanol increased the hepatic release of tumor necrosis factor-alpha, transforming growth factor-betal, interleukin (IL)-Ibeta and IL-6. Histological data showed that ethanol induced necrosis and inflammatory cell infiltration,
\end{abstract}

This article is freely accessible online.

\#These two Authors contributed equally to this study.

Correspondence to: Mei-Chin Yin, Department of Food Nutrition and Health Biotechnology, Asia University, Taichung, Taiwan, R.O.C. Tel: +886 423323456 ext. 1726, Fax: +886 423321206, e-mail: mcyin@hotmail.com.tw

Key Words: Oridonin, ethanol, hepatotoxicity, Nrf2, myeloperoxidase, p38. while Ori supplements alleviated these inflammatory responses. Ethanol up-regulated the hepatic mRNA expression of nuclear factor kappa B, myeloperoxidase and p38. Ori supplements reversed these changes. Conclusions: These novel findings suggest that Ori could be used as a potent agent against alcohol-induced hepatotoxicity.

Alcohol abuse is a worldwide public health issue because it causes high prevalence of alcoholic liver disorders (1). The typical pathological characteristics of alcoholic hepatotoxicity due to excessive and chronic ethanol intake include oxidative, glycative and inflammatory injury $(2,3)$. Ethanol and its major metabolite, acetaldehyde, promote hepatic cytochrome P4502E1 (CYP2E1) activity and impair the nuclear factor E2-related factor 2 (Nrf2)-associated antioxidant system (4). These events subsequently lead to the overproduction of reactive oxygen species (ROS) and nitric oxide (NO), and deplete glutathione (GSH) in liver, which finally increase hepatic oxidative stress (5). In addition, acetaldehyde can react with $\mathrm{N}$-ethyl amino groups to form advanced glycation end-products (AGEs) (6). AGEs, such as $\mathrm{N}^{\mathrm{e}}$-(carboxyethymethyl)-lysine (CML), N-ethyllysine or pentosidine, have been detected in the liver of patients with alcoholic hepatic diseases (7). A key enzyme, aldose reductase (AR), responsible for AGEs formation has been shown to be up-regulated in alcoholic liver disease (8).

At the same time, ethanol activates nuclear factor kappa B (NF-kB) and mitogen-activated protein kinase (MAPK) pathways, which result in the release of down-stream inflammatory mediators and cytokines, such as myeloperoxidase (MPO), tumor necrosis factor (TNF)-alpha, transforming growth factor (TGF)-beta1, interleukin (IL)1 beta and IL- 6 in the liver $(9,10)$. These mediators and cytokines enhance the inflammatory stress in the liver. Furthermore, oxidative, glycative and inflammatory stress from ethanol overdose not only induce hepatic cell apoptosis 
and immune malfunction, but also promote the development of liver cirrhosis or cancer (11). Therefore, any agent that can potentially ameliorate oxidative, glycative or inflammatory injury could, in theory, be able to protect liver against ethanol.

Oridonin (Ori) is a diterpenoid naturally present in some medicinal plants, such as Rabdosia rubescens, Isodon serra and Rabdosia excisa $(12,13)$. These plants or herbs are often used in traditional Chinese medicine. Lin et al. (14) have reported that Ori modulates glutathione homeostasis to decrease oxidative stress in nerve growth factor-differentiated PC12 cells. The study of Du et al. (15) has revealed that Ori could exert an anti-oxidative activity against arsenic-induced cellular toxicity by activating Nrf2-regulated antioxidant defensive responses. It is reported that through limiting NF$\mathrm{KB}$ and MAPK activation Ori can exhibit an antiinflammatory activity in endothelial cells (16). Taken together, these studies suggest that Ori bears both antioxidative and anti-inflammatory properties, however, the antiglycative effect of Ori remains unclear. The hepatic protection from Ori has received some attention $(17,18)$. Zheng et al. (17) have found that Ori supplementation can improve the hepatic mRNA expression of antioxidant enzymes, such as glutathione peroxidase (GPX) and catalase in lipopolysaccharide-challenged broilers. Deng et al. (18) have indicated that Ori could ameliorate D-galactosamine-induced inflammatory and apoptotic injury in the mouse liver. Even though these researches already suggest that Ori may be a hepatic protective agent, it is not known whether Ori could attenuate alcoholic hepatotoxicity.

In the present study, the hepatic anti-oxidative, antiglycative and anti-inflammatory protection of mice from two doses of chronic ethanol intake using Ori was evaluated. The effects of Ori upon associated indicators, as well as the activity and/or mRNA expression of CYP2E1, Nrf2, AR, NF-kB, p38 and MPO were analyzed. These results could support further studies or clinical trials for justifying the use of Ori to prevent or alleviate alcoholic hepatotoxicity.

\section{Materials and Methods}

Materials. Ori (98\%) was obtained from Sigma-Aldrich Co. (St. Louis, MO, USA). Lieber-DeCarli liquid ethanol diets were purchased from Dyets Inc. (Bethlehem, PA, USA). Male C57BL/6 male at 4 weeks old were purchased from National Laboratory Animal Center (Taipei City, Taiwan, ROC). Mice were maintained in standard conditions with temperature at $22 \pm 2^{\circ} \mathrm{C}$, relative humidity

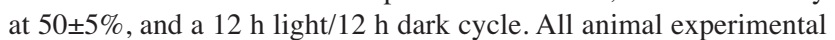
procedures regarding animal care, treatments and sacrifice strictly followed the Guide for the Care and Use of Laboratory Animals, and were approved by the laboratory animal's use and care of Asia University (permission no. 104-asia-05).

Experimental design. Dry powder of Ori at 0.125 or $0.25 \mathrm{~g}$ was mixed with 99.975 or $99.75 \mathrm{~g}$ standard basal diet (LabDiet Co., Fort Worth, TX, USA). After one-week acclimation, mice were randomly arranged
Table I. Primer sequences of target genes for RT-PCR analyses.

\begin{tabular}{lll}
\hline Target & & Primer \\
\hline Nrf2 & F & 5'-CTC GCT GGA AAA AGA AGT G-3' \\
& R & 5'-CCG TCC AGG AGT TCA GAG G-3' \\
HO-1 & F & 5'-TAA GAC CGC CTT CCT GCT CAA CAT-3' \\
& R & 5'-TGC TGG TTT CAA AGT TCA GGC CAC-3' \\
AR & F & 5'-GGACCTCTACCTTATTCACTG-3' \\
& R & 5'-TTGGCCCAGGGCCTGTCAG-3' \\
RAGE & F & 5'-GCT GTA GCT GGT GGT CAG AAC A-3' \\
& R & 5'-CCC CTT ACA GCT TAG CAC AAG TG-3' \\
NF-\&'B & F & 5'-GTA ACA GCA GGA CCC AAG GA-3' \\
& R & 5'-AGC CCC TAA TAC ACG CCT CT-3' \\
MPO & F & 5'-GGA AGG AGA CCT AGA GGT TGG-3' \\
& R & 5'-TAG CAC AGG AAG GCC AAT G-3' \\
p38 & F & 5'-ACT CAG ATG CCG AAG ATG AAC-3' \\
& R & 5'-GTG CTC AGG ACT CCA TCT CT-3' \\
GAPDH & F & 5'-GGA TGC AGG GAT GAT GTT C-3' \\
& R & 5'-TGC ACC ACC AAC TGC TTA G-3' \\
\hline
\end{tabular}

to five groups: i) normal diet group (ND), ii) Ori group (0.25\% Ori), iii) Lieber-DeCarli liquid ethanol diet group (ethanol diet, ED), iv) ethanol diet plus $0.125 \%$ Ori (ED+Ori, 0.125) and v) ethanol diet plus $0.25 \%$ Ori (ED+Ori, 0.25). Lieber-DeCarli liquid ethanol diet was purchased from Dyets, Inc. and supplied in drinking water bottles. This diet carries $36 \%$ of total energy from ethanol. In this study, liquid diet without ethanol was not used because our previous animal study (3) indicated that this non-ethanol diet did not cause significant differences in all examined factors when compared to the normal group. Body weight was measured weekly. Daily food intake was recorded. Following 8 weeks of supplementation, mice were euthanized using carbon dioxide after overnight fast. Blood was withdrawn, and then immediately centrifuged to collect the plasma. Partial liver tissue was homogenized in $2 \mathrm{ml}$ phosphate buffered saline (PBS, pH 7.4). The protein concentration of plasma or hepatic homogenate was measured using a Pierce BCA protein assay kit (Thermo Fisher Scientific Co., Waltham, MA, USA), in which uses bovine serum albumin serial dilutions to create a standard curve for protein concentration determination. Plasma was used for determining the activity of alanine transaminase (ALT) and aspartate transaminase (AST) by Randox ALT assay kit and Randox AST assay kit (Randox Lab. Ltd., Crumlin, UK).

Analyses of oxidative, glycative and inflammatory factors. Hepatic homogenate at $150 \mathrm{mg}$ was mixed with $2 \mathrm{mg} / \mathrm{ml} \mathrm{2',7'-}$ dichlorofluorescein diacetate for ROS measurement. Following incubation for $30 \mathrm{~min}$ at $37^{\circ} \mathrm{C}$, fluorescence values were read at 525 $\mathrm{nm}$ and $488 \mathrm{~nm}$ using a microplate reader (Molecular Devices, Sunnyvale, CA, USA). Data were shown as relative fluorescence unit (RFU) per mg of protein. NO content was measured by an Abcam nitric oxide assay kit (Abcam Co., Cambridge, UK), and quantified according to a sodium nitrite standard curve. GSH level was measured using a GSH-assay kit obtained from Biosciences Inc. (San Diego, CA, USA). Hepatic activity of glutathione reductase (GR), GPX or catalase was determined by GR-, GPX- or catalase-assay kits purchased from OxisResearch Co. (Portland, OR, USA). Hepatic CML level was measured by a CML-assay kit obtained from Roche Diagnostics (Penzberg, Germany). In brief, liver homogenate at 200 
Table II. Ori changed mice physiological characteristics. Initial body weight (BW, g), final BW ( $\mathrm{g}), \mathrm{BW}$ gain ( $\mathrm{g}$ ), food intake (FI, g/mouselday), liver weight $(L W, g)$, and plasma activity $(U / L)$ of ALT and AST in mice treated with normal diet $(N D)$, Ori alone $(0.25 \%$ Ori), ethanol diet (ED, Lieber-DeCarli liquid diet with ethanol), ED+Ori $(0.125 \%)$ and ED+Ori $(0.25 \%)$ for 8 weeks. Values are mean $\pm S D, n=8 .{ }^{a}-d$ Values in a row without a common letter differ, $p<0.05$.

\begin{tabular}{lccccc}
\hline & ND & Ori, 0.25 & ED & ED+Ori, 0.125 & ED+Ori, 0.25 \\
\hline Initial BW & $20.6 \pm 1.3^{\mathrm{a}}$ & $19.8 \pm 0.9^{\mathrm{a}}$ & $20.8 \pm 0.7^{\mathrm{a}}$ & $19.9 \pm 1.1^{\mathrm{a}}$ & $20.3 \pm 0.6^{\mathrm{a}}$ \\
Final BW & $27.4 \pm 1.0^{\mathrm{c}}$ & $26.9 \pm 0.6^{\mathrm{c}}$ & $24.5 \pm 1.2^{\mathrm{a}}$ & $25.8 \pm 0.8^{\mathrm{b}}$ & $26.1 \pm 0.7^{\mathrm{b}}$ \\
BW gain & $6.1 \pm 0.7^{\mathrm{c}}$ & $5.9 \pm 0.8^{\mathrm{c}}$ & $4.0 \pm 0.6^{\mathrm{a}}$ & $5.3 \pm 0.5^{\mathrm{b}}$ & $5.5 \pm 0.4^{\mathrm{b}}$ \\
FI & $2.3 \pm 0.3^{\mathrm{a}}$ & $2.4 \pm 0.4^{\mathrm{a}}$ & $2.0 \pm 0.6^{\mathrm{a}}$ & $2.1 \pm 0.5^{\mathrm{a}}$ & $2.2 \pm 0.4^{\mathrm{a}}$ \\
LW & $1.37 \pm 0.06^{\mathrm{a}}$ & $1.33 \pm 0.04^{\mathrm{a}}$ & $1.76 \pm 0.11^{\mathrm{c}}$ & $1.61 \pm 0.07^{\mathrm{b}}$ & $1.42 \pm 0.04^{\mathrm{a}}$ \\
ALT & $20 \pm 2^{\mathrm{a}}$ & $22 \pm 5^{\mathrm{a}}$ & $122 \pm 13^{\mathrm{d}}$ & $96 \pm 8^{\mathrm{c}}$ & $51 \pm 6^{\mathrm{b}}$ \\
AST & $21 \pm 4^{\mathrm{a}}$ & $23 \pm 3^{\mathrm{a}}$ & $143 \pm 10^{\mathrm{d}}$ & $107 \pm 11^{\mathrm{c}}$ & $64 \pm 7^{\mathrm{b}}$ \\
\hline
\end{tabular}

Table III. Ori ameliorated hepatic oxidative damage. Hepatic levels of ROS (RFU/mg protein), NO (umol/mg protein), GSH (nmol/mg protein), and activity (U/mg protein) of GPX, GR and catalase in mice treated with normal diet (ND), Ori alone (0.25\% Ori), ethanol diet (ED, Lieber-DeCarli liquid diet with ethanol), ED+Ori $(0.125 \%)$ and $E D+$ Ori $(0.25 \%)$ for 8 weeks. Values are mean $\pm S D, n=8$. a-dValues in a row without a common letter differ, $p<0.05$.

\begin{tabular}{|c|c|c|c|c|c|}
\hline & ND & Ori, 0.25 & ED & $\mathrm{ED}+$ Ori, 0.125 & $\mathrm{ED}+$ Ori, 0.25 \\
\hline ROS & $0.21 \pm 0.06^{\mathrm{a}}$ & $0.19 \pm 0.08^{\mathrm{a}}$ & $1.70 \pm 0.18^{\mathrm{d}}$ & $1.24 \pm 0.11^{\mathrm{c}}$ & $0.72 \pm 0.14^{b}$ \\
\hline NO & $0.57 \pm 0.07^{\mathrm{a}}$ & $0.53 \pm 0.05^{\mathrm{a}}$ & $1.49 \pm 0.12^{\mathrm{a}}$ & $1.08 \pm 0.1^{\mathrm{b}}$ & $0.91 \pm 0.09^{b}$ \\
\hline GSH & $12.4 \pm 1.3^{\mathrm{c}}$ & $12.7 \pm 0.8^{c}$ & $6.7 \pm 0.8^{\mathrm{a}}$ & $8.6 \pm 1.0^{\mathrm{b}}$ & $10.5 \pm 0.6^{\mathrm{b}}$ \\
\hline GPX & $19.3 \pm 1.6^{\mathrm{d}}$ & $19.6 \pm 1.1^{\mathrm{d}}$ & $12.6 \pm 0.8^{\mathrm{a}}$ & $14.7 \pm 1.0^{\mathrm{b}}$ & $16.9 \pm 1.3^{\mathrm{c}}$ \\
\hline GR & $1.70 \pm 0.13^{\mathrm{c}}$ & $1.68 \pm 0.08^{\mathrm{c}}$ & $0.76 \pm 0.07^{\mathrm{a}}$ & $1.13 \pm 0.15^{b}$ & $1.24 \pm 0.09^{b}$ \\
\hline Catalase & $18.1 \pm 1.0^{\mathrm{c}}$ & $18.4 \pm 0.6^{\mathrm{c}}$ & $11.8 \pm 1.2^{\mathrm{a}}$ & $13.7 \pm 0.9^{b}$ & $16.9 \pm 1.5^{\mathrm{c}}$ \\
\hline
\end{tabular}

mg was mixed with a CML-specific 4G9 monoclonal antibody (Roche Diagnostics). CML level was detected at 405 and $603 \mathrm{~nm}$, and calibrated according to a curve created by 6-(N-carboxymethylamino) caproic acid. Hepatic pentosidine level was analyzed by using a highperformance liquid chromatography (HPLC, model 510, Waters, Tokyo, Japan) method described by Scheijen et al. (19). This HPLC system was composed of a fluorescence detector (model 470, Waters) and a C18 column (reverse-phase, $3 \mathrm{~mm}, 4.6 \times 100 \mathrm{~mm}$ ). The wavelength of excitation and emission was set at $335 \mathrm{~nm}$ and $385 \mathrm{~nm}$, respectively. Hepatic levels of TNF-alpha, TGF-beta1, IL-1beta and IL-6 were analyzed using the TNFalpha-, TGFbeta1-, IL1beta- and IL6-assay kits purchased from BioLegend Co. (San Diego, CA, USA).

Assays of CYP2E1, AR, NF- $k B$ binding and MPO activities. Hepatic CYP2E1 activity was determined by tracing the formation rate of $\mathrm{p}$ nitrocatechol from p-nitrophenol (PNP) (20). The reaction mixture consisted of $200 \mu \mathrm{g}$ liver homogenate, $0.2 \mathrm{mM}$ PNP and $100 \mathrm{mM}$ potassium-phosphate buffer ( $\mathrm{pH} 7.4)$. NADPH at $1 \mathrm{mM}$ was added to initiate the reaction. After incubation at $37^{\circ} \mathrm{C}$ for $1 \mathrm{~h}, 30 \mu \mathrm{l}$ of $20 \%$ trichloroacetic acid were added to stop the reaction. The supernatant was collected and was mixed with sodium hydroxide. The absorbance at $546 \mathrm{~nm}$ was monitored, and CYP2E1 activity was shown as $\mathrm{pmol} / \mathrm{min} / \mathrm{mg}$ protein. Hepatic AR activity was assessed by the method of Ji et al. (21), by monitoring the decrease of NADPH at $340 \mathrm{~nm}$. The reaction mixture consisted of $150 \mu \mathrm{g}$ liver homogenate, $160 \mathrm{nM} \mathrm{NADPH}, 0.4 \mathrm{M}\left(\mathrm{NH}_{4}\right)_{2} \mathrm{SO}_{4}, 10 \mathrm{mM} \mathrm{DL}-$ glyceraldehyde and $100 \mathrm{mM}$ PBS (pH 6.2). Following a 7 min reaction at $25^{\circ} \mathrm{C}$, the sample was placed in a $-20^{\circ} \mathrm{C}$ freezer to terminate the reaction. NF- $\mathrm{KB}$ p50/65 binding activity was quantified using the NF-kB binding assay kit (Chemicon Int. Co., Temecula, CA, USA). Nuclear protein was extracted from liver tissue, and this extract at $10 \mathrm{mg}$ was mixed with $3,3^{\prime}, 5,5^{\prime}$-tetramethylbenzidine, followed by incubation for $1 \mathrm{~h}$ at $25^{\circ} \mathrm{C}$. The sample was further mixed with a horseradish peroxidase-conjugated antibody (Roche Diagnostics), followed by an additional incubation of another $1 \mathrm{~h}$ at $25^{\circ} \mathrm{C}$. Optical density (OD) value at $450 \mathrm{~nm}$ was read using a microplate reader (Molecular Devices). The result was expressed as an OD value per mg protein. Hepatic MPO activity was measured by the method of da Silva-Santi et al. (22). Following hepatic homogenate centrifugation, $10 \mathrm{ml}$ supernatant was mixed with 200 $\mathrm{ml}$ PBS containing $1 \% \mathrm{H}_{2} \mathrm{O}_{2}$ and o-dianisidine dihydrochloride. This enzymic reaction was terminated by adding sodium acetate. MPO activity was determined by reading the absorbance at $460 \mathrm{~nm}$. Data are shown as folds of normal groups.

Histological evaluation. Partial hepatic tissue from each mouse was soaked in $4 \%$ paraformaldehyde for fixation. Dehydration was processed by increasing ethanol concentration, and xylene was used for clearing. Then, each sample was embedded in paraffin and was sectioned at $5 \mathrm{~mm}$ thickness and used for hematoxylin and eosin (H\&E) stain. The histological result was evaluated under a light microscope (model: IX71, Olympus, Tokyo, Japan). 


\section{CYP2E1 activity}

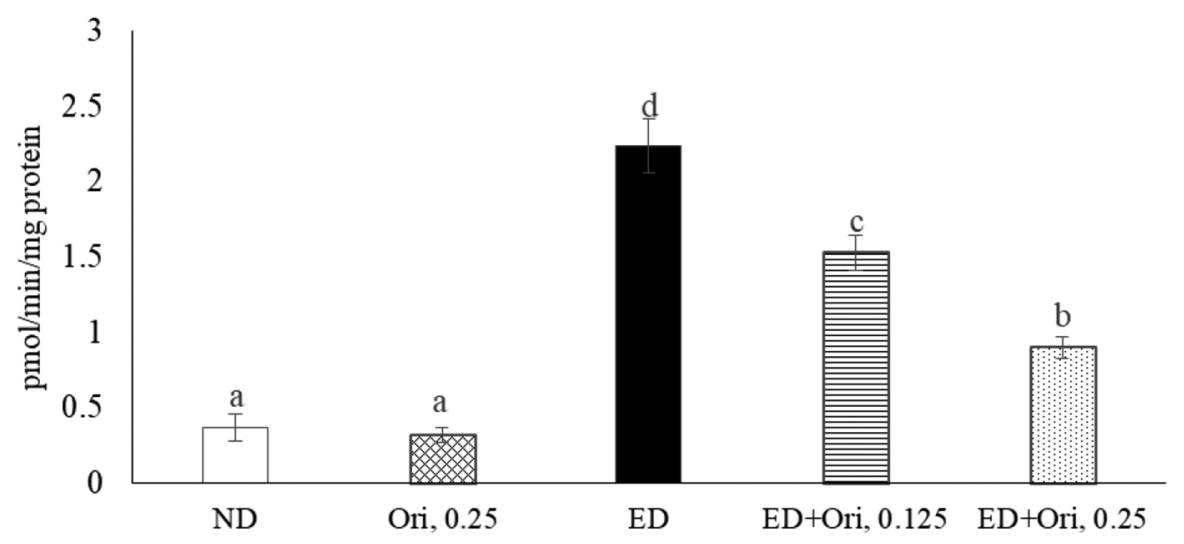

mRNA expression

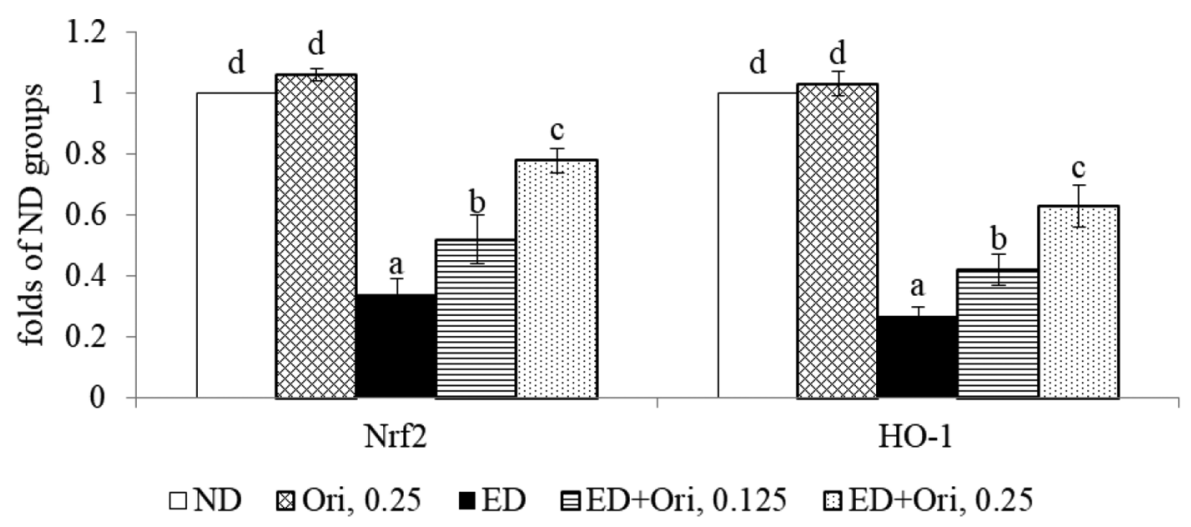

Figure 1. Ori altered hepatic CYP2E1 activity and mRNA expression of Nrf2 and HO-1. Mice treated with normal diet (ND), Ori alone (0.25\% Ori), ethanol diet (ED, Lieber-DeCarli liquid diet with ethanol), ED+Ori $(0.125 \%)$ and ED+Ori $(0.25 \%)$ for 8 weeks were tested for hepatic CYP2E1 activity and mRNA expression of Nrf2 and HO-1. Values are mean $\pm S D, n=8 .{ }^{a-d}$ Values among bars without a common letter differ, $p<0.05$.

Determination of mRNA expression. Hepatic mRNA expression was measured using real-time polymerase chain reaction (RT-PCR). Total RNA of $100 \mathrm{mg}$ liver tissue was extracted using TRIzol ${ }^{\circledR}$ reagents purchased from Life Technologies (Grand Island, NY, USA). The concentration of total RNA was determined by reading the absorbance at $260 \mathrm{~nm}$. An amount of $2 \mathrm{mg}$ RNA was further used for cDNA synthesis using a cDNA-synthesis kit obtained from Legene Biosciences. Subsequently, the synthesized cDNA was used for RT-PCR procedure in which the fluorescent dye was SYBR Premix Ex TaqTM II. RT-PCR was processed by a real-time system (AB7500, Applied Biosystems, Foster City, CA, USA). The primers of target factors used for PCR are shown in Table I. Glyceraldehyde-3-phosphate dehydrogenase (GAPDH), a house keeping gene, was used to normalize the mRNA expression.

Statistical analysis. Data are expressed as means \pm standard deviation (SD) from 8 mice $(\mathrm{n}=8)$. One-way ANOVA was applied to assess any significant differences. Tukey's post hoc test was used to determine the differences between groups. When the $p$-Value was less than 0.05 , the difference was considered statistically significant.

\section{Results}

Ori improved liver function and oxidative stress. As shown in Table II, ethanol intake lowered BW gain and increased liver weight, ALT and AST activities $(p<0.05)$, while. Ori supplementation at both doses increased BW gain, reduced liver weight, ALT and AST activities $(p<0.05)$. Ethanol increased the production of ROS and NO, decreased GSH content, and lowered the activity of GPX, GR and catalase (Table III, $p<0.05$ ), and Ori supplemented at the two doses reversed these changes $(p<0.05)$. Compared to the ethanol groups, Ori supplementation at either of the two doses reduced the CYP2E1 activity (Figure 1, $p<0.05$ ). Finally, ethanol suppressed the hepatic mRNA expression of Nrf2 and heme oxygenase (HO)$1(p<0.05)$, while Ori increased them both $(p<0.05)$.

Ori alleviated hepatic glycative stress. Ethanol increased the hepatic CML and pentosidine levels, and enhanced AR 


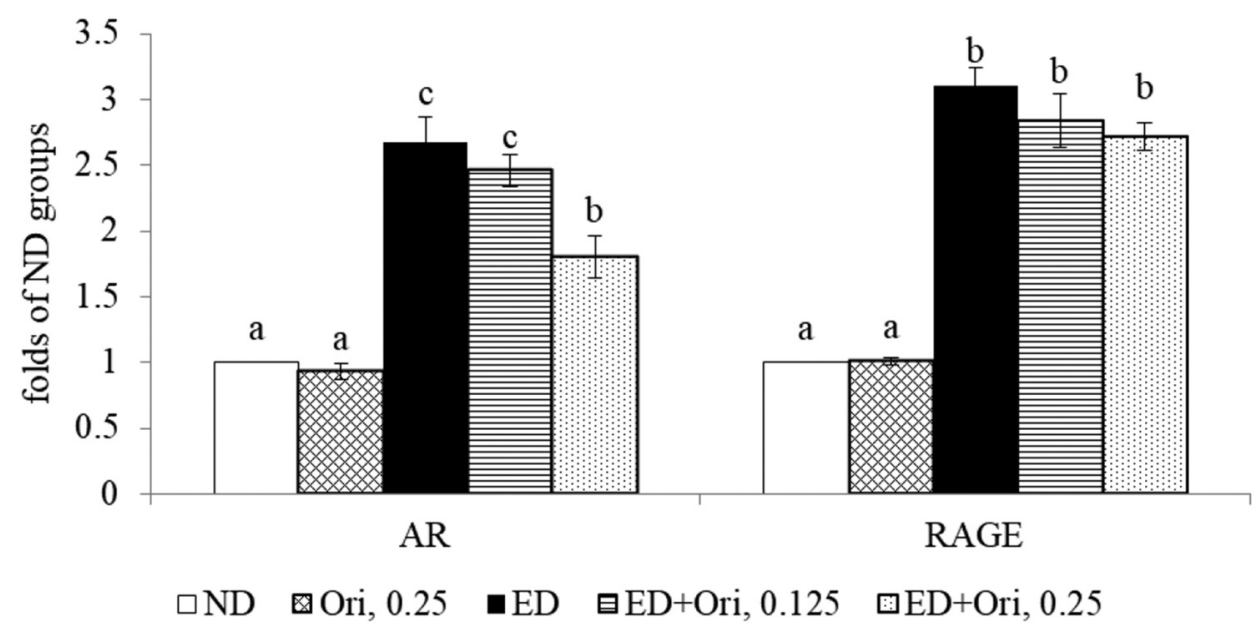

Figure 2. Ori affected hepatic mRNA expression of AR and RAGE. Mice treated with normal diet (ND), Ori alone (0.25\% Ori), ethanol diet (ED, Lieber-DeCarli liquid diet with ethanol), ED+Ori $(0.125 \%)$ and ED+Ori $(0.25 \%)$ for 8 weeks were tested for hepatic mRNA expression of AR and $R A G E$. Values are mean $\pm S D, n=8 .{ }^{a-c}$ Values among bars without a common letter differ, $p<0.05$.

ND

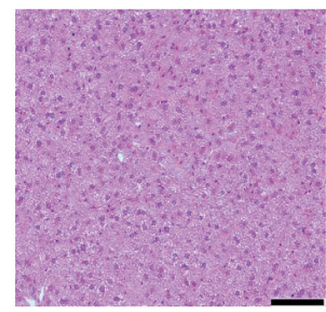

Ori, 0.25

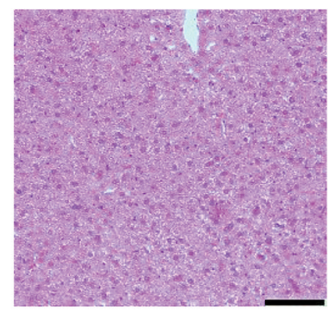

$\mathrm{ED}$

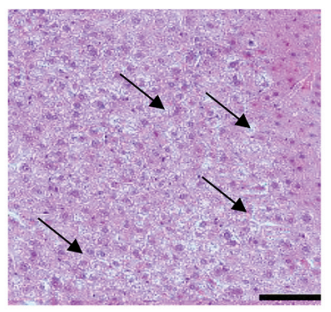

ED+Ori, 0.125

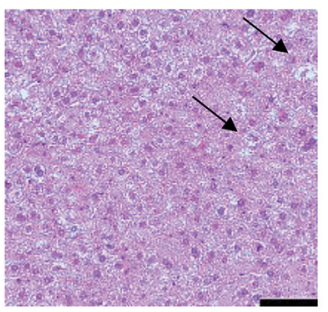

ED+Ori, 0.25

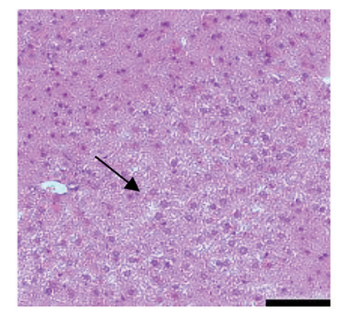

Figure 3. Ori improved histological characteristics. Effects of ethanol and/or Oridonin upon hepatic damage examined by hematoxylin and eosin stain in mice treated with normal diet (ND), Ori alone (0.25\% Ori), ethanol diet (ED, Lieber-DeCarli liquid diet with ethanol), ED+Ori $(0.125 \%)$ and $E D+O r i(0.25 \%)$ for 8 weeks. Scale bar $=50 \mu \mathrm{m}$. Arrows indicate necrosis.

Table IV. Ori attenuated hepatic glycative stress. Hepatic level of CML (pmol/mg protein) and pentosidine (pmol/mg protein), and AR activity $(\mathrm{nmol} / \mathrm{min} / \mathrm{mg}$ protein) in mice treated with normal diet $(\mathrm{ND})$, Ori alone $(0.25 \%$ Ori), ethanol diet (ED, Lieber-DeCarli liquid diet with ethanol), $E D+\operatorname{Ori}(0.125 \%)$ and $E D+\operatorname{Ori}(0.25 \%)$ for 8 weeks. Values are mean $\pm S D, n=8 .{ }^{a-c}$ Values in a row without a common letter differ, $p<0.05$.

\begin{tabular}{lccccc}
\hline & ND & Ori, 0.25 & ED & ED+Ori, 0.125 & ED+Ori, 0.25 \\
\hline CML & $0.42 \pm 0.09^{\mathrm{a}}$ & $0.37 \pm 0.06^{\mathrm{a}}$ & $2.67 \pm 0.21^{\mathrm{c}}$ & $2.39 \pm 0.16^{\mathrm{c}}$ & $1.90 \pm 0.12^{\mathrm{b}}$ \\
Pentosidine & $0.08 \pm 0.03^{\mathrm{a}}$ & $0.07 \pm 0.05^{\mathrm{a}}$ & $0.41 \pm 0.08^{\mathrm{c}}$ & $0.35 \pm 0.05^{\mathrm{c}}$ & $0.21 \pm 0.06^{\mathrm{b}}$ \\
AR & $0.34 \pm 0.08^{\mathrm{a}}$ & $0.32 \pm 0.09^{\mathrm{a}}$ & $1.87 \pm 0.19^{\mathrm{c}}$ & $1.68 \pm 0.11^{\mathrm{c}}$ & $1.03 \pm 0.14^{\mathrm{b}}$ \\
\hline
\end{tabular}

activity (Table IV, $p<0.05$ ). Ori supplementation at a single high dose, $0.25 \%$, decreased CML and pentosidine levels, and lowered the AR activity $(p<0.05)$. As shown in Figure 2, ethanol up-regulated the hepatic AR and RAGE mRNA expression $(p<0.05)$, while a single dose of Ori at $0.25 \%$ suppressed AR mRNA expression $(p<0.05)$. Ori supplements at two doses slightly lowered RAGE mRNA expression $(p>0.05)$, albeit not significantly.

Ori ameliorated hepatic inflammatory stress. As presented in histological images (Figure 3), ethanol induced hepatic cell necrosis and inflammatory cell infiltration. Ori supplementation 
Table V. Ori decreased hepatic inflammatory cytokines. Hepatic levels (pg/mg protein) of TNF-alpha, TGF-beta1, IL-1beta and IL-6 were measured in mice treated with normal diet (ND), Ori alone (0.25\% Ori), ethanol diet (ED, Lieber-DeCarli liquid diet with ethanol), ED+Ori (0.125\%) and $E D+$ Ori $(0.25 \%)$ for 8 weeks. Values are mean $\pm S D, n=8$. a-dValues in a row without a common letter differ, $p<0.05$.

\begin{tabular}{lccccc}
\hline & ND & Ori, 0.25 & ED & ED+Ori, 0.125 & ED+Ori, 0.25 \\
\hline TNF-alpha & $19 \pm 6^{\mathrm{a}}$ & $17 \pm 4^{\mathrm{a}}$ & $213 \pm 15^{\mathrm{d}}$ & $158 \pm 13^{\mathrm{c}}$ & $89 \pm 10^{\mathrm{b}}$ \\
TGF-beta1 & $23 \pm 3^{\mathrm{a}}$ & $20 \pm 5^{\mathrm{a}}$ & $174 \pm 12^{\mathrm{c}}$ & $103 \pm 5^{\mathrm{b}}$ & $94 \pm 8^{\mathrm{b}}$ \\
IL-1beta & $16 \pm 4^{\mathrm{a}}$ & $18 \pm 3^{\mathrm{a}}$ & $168 \pm 17^{\mathrm{d}}$ & $120 \pm 11^{\mathrm{c}}$ & $75 \pm 6^{\mathrm{b}}$ \\
IL-6 & $21 \pm 5^{\mathrm{a}}$ & $23 \pm 4^{\mathrm{a}}$ & $185 \pm 14^{\mathrm{d}}$ & $126 \pm 7^{\mathrm{c}}$ & $82 \pm 9^{\mathrm{b}}$ \\
\hline
\end{tabular}

at both doses attenuated the inflammatory infiltration. Ethanol increased the hepatic release of TNF-alpha, TGF-beta1, IL1beta and IL-6 (Table V, $p<0.05$ ), however, Ori supplementation at both doses decreased the production of these inflammatory cytokines $(p<0.05)$. As presented in Figures 4 and 5, ethanol increased the hepatic NF- $\mathrm{KB}$ binding activity and up-regulated the hepatic mRNA expression of NF-kB, MPO and p38 $(p<0.05)$. Ori supplementation at either of the two doses reduced the NF-kB binding activity and down-regulated the mRNA expression of NF-kB, MPO and p38 $(p<0.05)$.

\section{Discussion}

Chronic or excessive ethanol consumption can cause hepatic oxidative, glycative and inflammatory injury (7). In our present study we have observed that ethanol intake in mice limited the mRNA expression of $\mathrm{Nrf} 2$ and $\mathrm{HO}-1$, and stimulated the mRNA expression of AR, RAGE, NF-kB, MPO and p38 in the liver. These events consequently resulted in the overproduction of oxidants, AGEs and inflammatory cytokines in that tissue. Interestingly, we found that Ori treatments effectively alleviated the ethanol-elicited oxidative, glycative and inflammatory stress through mediating both activity and mRNA expression of associated factors. Histological data also supported that Ori supplements at either dose improved the ethanol-induced hepatic necrotic and inflammatory features. These novel findings suggest that Ori is a potent protective agent for the liver against ethanol.

Ethanol and its metabolites, such as acetaldehyde, are able to enhance the CYP2E1 activity, and impair the antioxidant defensive system by suppressing the mRNA expression of Nrf2 and HO-1 in the liver (23), which subsequently leads to the overproduction of ROS and NO, depletion of GSH, and reduction of antioxidant enzymic activities. In our present study, Ori supplements at either dose markedly diminished the CYP2E1 activity, which in turn contributed to lowering ROS generation. Nrf2 is a transcription factor involved in endogenous antioxidant cell protection. Nrf2 can mediate the expression of phase II detoxifying enzymes and antioxidant genes through the actions of antioxidant-response elements (AREs) (24), such as HO-1, which is a Nrf2 target gene (25). We found that Ori treatments up-regulated the mRNA expression of Nrf2 and HO-1, which subsequently led to an increase in the GSH content, as well as the activity of GPX, GR and catalase in the liver. These changes definitely decreased ROS production caused by ethanol consumption. It is reported that ethanol induces NO overproduction, which can promote hemolysis (26). NO at high levels is considered a cytotoxic substance because it could form peroxynitrite to interfere with the function of biological molecules, such as the biomembrane phospholipids (27). In our present work, Ori treatments mitigated the ethanolinduced NO overproduction, which not only attenuated the hepatic oxidative injury but also reduced the risk of hemolysis or peroxynitrite formation.

Glycative stress due to AGEs accumulation facilitates the pathological deterioration of alcoholic liver disorders. This happens because the interaction between AGEs and RAGEs activates many signaling pathways and facilitates the downstream generation of oxidants, inflammatory mediators and even apoptotic factors, which consequently cause hepatic malfunctions and may induce hepatic cirrhosis or cancer (6). In this study, although Ori treatments failed to affect RAGE mRNA expression, Ori supplement at $0.25 \%$ effectively reduced the hepatic activity and the mRNA expression of AR, a rate-limiting enzyme involved in AGEs formation. Subsequently, the lower AR activity and mRNA expression decreased the hepatic CML and formation of pentosidine. These results revealed that Ori could diminish hepatic glycative stress through limiting the AR pathway. Thus, Ori seems to act as a novel AR inhibitor. Shi et al. (8) have reported that an AR inhibitor could alleviate ethanol-induced hepatic oxidative and inflammatory stress. Apparently, the influence of Ori on AR may also contribute to alleviate the ethanol-induced hepatic oxidative and inflammatory injury. In addition, Ori treatments diminished AGEs formation and, thus, the available AGEs to engage with RAGE were fewer. Consequently, we observed lower levels of activation of signaling pathways, such as NF-kB and p38, in the liver of Ori-treated mice. These data suggest that the anti-glycative action of Ori provided a benefit towards the attenuation of hepatic oxidative and inflammatory stress. 


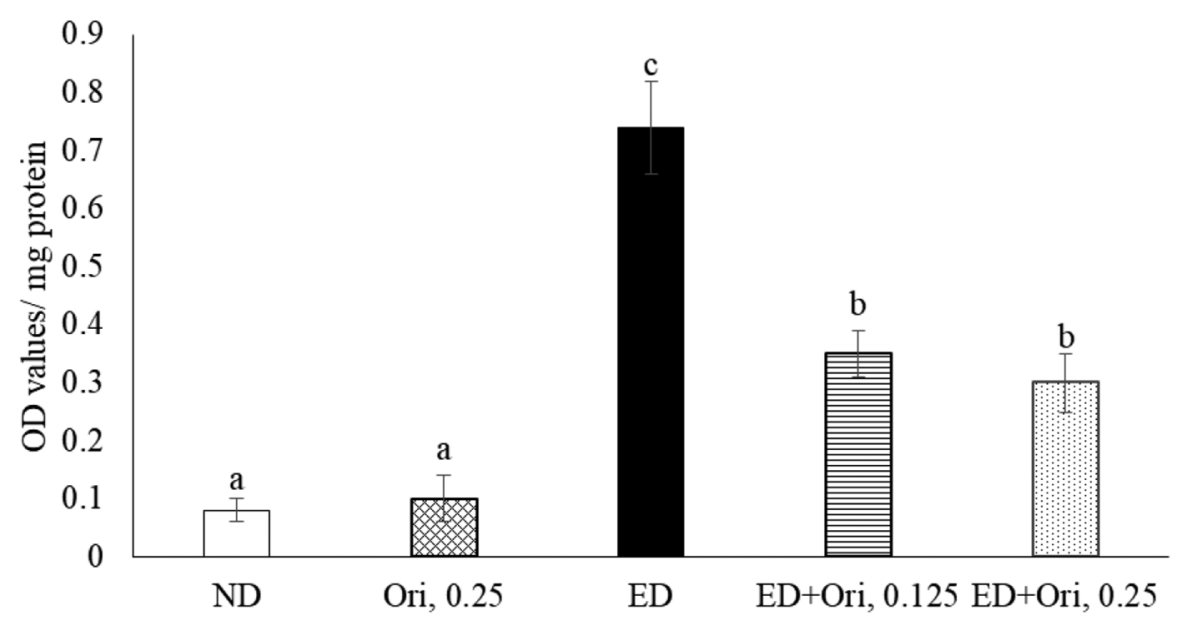

Figure 4. Ori lowered the hepatic NF- $k B$ binding activity. Mice were treated with normal diet (ND), Ori alone (0.25\% Ori), ethanol diet (ED, LieberDeCarli liquid diet with ethanol), ED+Ori $(0.125 \%)$ and ED+Ori $(0.25 \%)$ for 8 weeks. The increase in NF-kB binding activity caused by ethanol was reversed by the addition of Ori in the diet of these mice. Values are mean $\pm S D, n=8 .{ }^{a-c}$ Values among bars without a common letter differ, $p<0.05$.

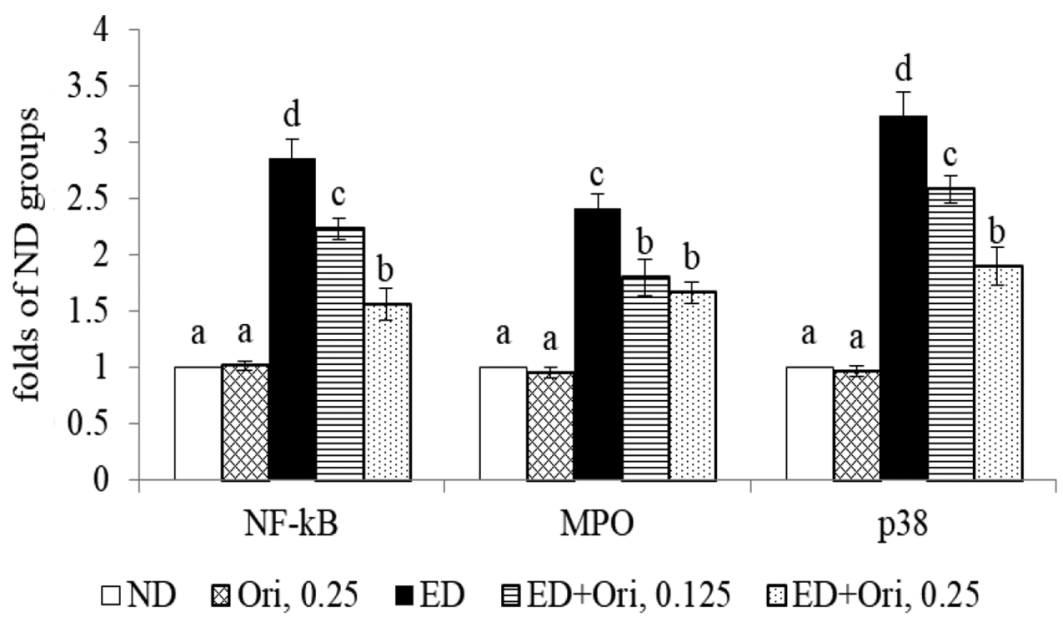

Figure 5. Ori suppressed hepatic mRNA expression of $N F-k B, M P O$ and p38. Mice were treated with normal diet (ND), Ori alone (0.25\% Ori), ethanol $\operatorname{diet}\left(E D\right.$, Lieber-DeCarli liquid diet with ethanol), ED+Ori $(0.125 \%)$ and $E D+$ Ori $(0.25 \%)$ for 8 weeks. Values are mean $\pm S D, n=8 .{ }^{a-d}$ Values among bars without a common letter differ, $p<0.05$.

From our histological data, we concluded that ethanol induced focal necrosis, as well as lymphocytic and neutrophilic infiltration. Biochemical analyses also indicated that ethanol promoted the release of inflammatory cytokines, including TNF-alpha, TGF-beta1, IL-1beta and IL-6. In the ethanoltreated mice, Ori supplements decreased the generation of these cytokines, and ameliorated the focal necrosis and inflammatory cell infiltration. Obviously, Ori treatments at the doses tested markedly mitigated the hepatic inflammatory injury induced by ethanol. It is reported that NF-kB and p38 are upstream inflammatory mediators, while the activation of NF-kB and p38 pathways stimulates the downstream production of inflammatory cytokines $(9,17)$. Our results revealed that Ori treatments counteracted the ethanol stimulation by limiting the $\mathrm{NF}-\mathrm{kB}$ binding activity and suppressing the mRNA expression of NF-kB and p38. Since the levels of NF-kB and p38 available were lower, the observed decrease in the formation of downstream inflammatory factors was reasonable. Consequently, it was expected that there will be a decrease in the plasma ALT and AST activities. MPO is a stimulator responsible for the production of cytotoxic oxidants and inflammatory factors (28). Ori treatments substantially downregulated the hepatic MPO mRNA expression, which also contributed to a reduction in oxidants and cytokines. In 
addition, it was interesting to find that Ori could effectively decrease the production of TGF-beta1 caused by ethanol. TGFbetal overproduction plays a crucial role in the progression of fibrosis (29). Our data suggest that Ori could be able to ameliorate hepatic fibrosis while additional studies could enforce on the assumption that Ori could also protect the liver from ethanol-induced cirrhosis abuse through several mechanisms.

In addition, it has been previously reported that Ori protects the liver from a lipopolysaccharide or Dgalactosamine-induced injury $(18,19)$. Our findings here extend the hepatic protective actions of Ori to alleviate the alcoholic hepatotoxicity. Ori is a diterpenoid available in several medicinal plants (13). Based on its natural properties, the intake of this compound or food rich in this agent should be safe. In our present work, Ori treatment alone did not affect any of the assessments we made. These results also suggest that Ori may not have any side effects at the doses used here. Ori supplementation at 0.125 or $0.25 \%$ for a mouse is approximately equal to 7 or $14 \mathrm{~g} /$ day for a $70-\mathrm{kg}$ adult man. These doses may be feasible for human practical applications. However, further animal studies regarding appropriate dosage, safety, function and efficiency of this agent are definitely necessary before it is used in humans.

In conclusion, oridonin effectively protected the mouse liver against ethanol-induced oxidative, glycative and inflammatory injury by regulating several important molecules. This compound should be further explored with regards to the possibility to have a preventive or ameliorative role in alcoholic liver disease.

\section{Conflicts of Interest}

All Authors declare that there are no conflicts of interest.

\section{Authors' Contributions}

YSL designed this study and was responsible for the project administration. HCS ran most experiments. MMC performed histological evaluation. YMC handled statistical analyses and wrote this manuscript.

\section{Acknowledgements}

This study was partially supported by a grant from Asia University, Taichung, Taiwan (ASIA-108-CMUH-03).

\section{References}

1 Niemelä O: Biomarker-based approaches for assessing alcohol use disorders. Int J Environ Res Public Health 13(2): 166, 2016. PMID: 26828506. DOI: 10.3390/ijerph13020166

2 Gao B and Bataller R: Alcoholic liver disease: pathogenesis and new therapeutic targets. Gastroenterology 141(5): 1572-1585, 2011. PMID: 21920463. DOI: 10.1053/j.gastro.2011.09.002
3 Yin MC, Wang ZH, Liu WH and Mong MC: Aqueous extract of Gynura bicolor attenuated hepatic steatosis, glycative, oxidative, and inflammatory injury induced by chronic ethanol consumption in mice. J Food Sci 82(11): 2746-2751, 2017. PMID: 29023845. DOI: 10.1111/1750-3841.13930

4 Bardag-Gorce F, Oliva J, Lin A, Li J, French BA and French SW: Proteasome inhibitor up regulates liver antioxidative enzymes in rat model of alcoholic liver disease. Exp Mol Pathol 90(1): 123-130, 2011. PMID: 21036165. DOI: 10.1016/ j.yexmp.2010.10.013

5 Kaur G, Jabbar Z, Athar M and Alam MS: Punica granatum (pomegranate) flower extract possesses potent antioxidant activity and abrogates Fe-NTA induced hepatotoxicity in mice. Food Chem Toxicol 44(7): 984-993, 2006. PMID: 16426722. DOI: $10.1016 /$ j.fct.2005.12.001

6 Hayashi N, George J, Takeuchi M, Fukumura A, Toshikuni N, Arisawa $\mathrm{T}$ and Tsutsumi $\mathrm{M}$ : Acetaldehyde-derived advanced glycation end-products promote alcoholic liver disease. PLoS One 8(7): e70034, 2013. PMID: 23922897. DOI: 10.1371/ journal.pone. 0070034

7 Eriksson CJ: The role of acetaldehyde in the actions of alcohol (update 2000). Alcohol Clin Exp Res 25(5 Suppl ISBRA): 15S-32S, 2001. PMID: 11391045. DOI: 10.1097/00000374-200105051-00005

8 Shi C, Wang Y, Gao J, Chen S, Zhao X, Cai C, Guo C and Qiu L: Inhibition of aldose reductase ameliorates alcoholic liver disease by activating AMPK and modulating oxidative stress and inflammatory cytokines. Mol Med Rep 16(3): 2767-2772, 2017. PMID: 28677809. DOI: 10.3892/mmr.2017.6895

9 Jaruga B, Hong F, Kim WH, Sun R, Fan S and Gao B: Chronic alcohol consumption accelerates liver injury in T cell-mediated hepatitis: alcohol disregulation of NF-kappaB and STAT3 signaling pathways. Am J Physiol Gastrointest Liver Physiol 287(2): G471-G479, 2004. PMID: 15064234. DOI: 10.1152/ ajpgi.00018.2004

10 Zima $\mathrm{T}$ and Kalousová M: Oxidative stress and signal transduction pathways in alcoholic liver disease. Alcohol Clin Exp Res 29(11 Suppl): 110S-115S, 2005. PMID: 16344594. DOI: 10.1097/01.alc.0000189288.30358.4b

11 Ambade A, Satishchandran A and Szabo G: Alcoholic hepatitis accelerates early hepatobiliary cancer by increasing stemness and miR-122-mediated HIF-1 $\alpha$ activation. Sci Rep 6: 21340 , 2016. PMID: 26888602. DOI: 10.1038/srep21340

12 Liu J, Yang F, Zhang Y and Li J: Studies on the cellimmunosuppressive mechanism of Oridonin from Isodon serra. Int Immunopharmacol 7(7): 945-954, 2007. PMID: 17499197. DOI: 10.1016/j.intimp.2007.03.001

$13 \mathrm{Wu}$ YX, Zhang W, Li JC and Liu N: Chemical constituents of flowers and fruits of Rabdosia excisa. Chin J Nat Med 10(1): 43-47, 2012. PMID: 23302530. DOI: 10.1016/S18755364(12)60010-7

14 Lin KH, Li CY, Hsu YM, Tsai CH, Tsai FJ, Tang CH, Yang JS, Wang ZH and Yin MC: Oridonin, a natural diterpenoid, protected NGF-differentiated PC12 cells against $\mathrm{MPP}^{+}-$and kainic acid-induced injury. Food Chem Toxicol 133: 110765, 2019. PMID: 31430510. DOI: 10.1016/j.fct.2019.110765

15 Du Y, Villeneuve NF, Wang XJ, Sun Z, Chen W, Li J, Lou H, Wong PK and Zhang DD: Oridonin confers protection against arsenic-induced toxicity through activation of the Nrf2-mediated defensive response. Environ Health Perspect 116(9): 1154-1161, 2008. PMID: 18795156. DOI: 10.1289/ehp.11464 
16 Huang W, Huang M, Ouyang H, Peng J and Liang J: Oridonin inhibits vascular inflammation by blocking NF- $\mathrm{kB}$ and MAPK activation. Eur J Pharmacol 826: 133-139, 2018. PMID: 29518395. DOI: 10.1016/j.ejphar.2018.02.044

17 Zheng XC, Wu QJ, Song ZH, Zhang H, Zhang JF, Zhang LL, Zhang TY, Wang $\mathrm{C}$ and Wang T: Effects of Oridonin on growth performance and oxidative stress in broilers challenged with lipopolysaccharide. Poult Sci 95(10): 2281-2289, 2016. PMID: 27143760. DOI: $10.3382 / \mathrm{ps} /$ pew 161

18 Deng Y, Chen C, Yu H, Diao H, Shi C, Wang Y, Li G and Shi $\mathrm{M}$ : Oridonin ameliorates lipopolysaccharide/D-galactosamineinduced acute liver injury in mice via inhibition of apoptosis. Am J Transl Res 9(9): 4271-4279, 2017. PMID: 28979700.

19 Scheijen JL, van de Waarenburg MP, Stehouwer CD and Schalkwijk CG: Measurement of pentosidine in human plasma protein by a single-column high-performance liquid chromatography method with fluorescence detection. J Chromatogr B Analyt Technol Biomed Life Sci 877(7): 610-614, 2009. PMID: 19188098. DOI: 10.1016/j.jchromb.2009.01.022

20 Yao HT, Yang YC, Chang CH, Yang HT and Yin MC: Protective effects of (-)-epigallocatechin-3-gallate against acetaminopheninduced liver injury in rats). Biomedicine (Taipei) 5(3): 15, 2015. PMID: 26264479. DOI: 10.7603/s40681-015-0015-8

21 Ji L, Li C, Shen N, Huan Y, Liu Q, Liu S and Shen Z: A simple and stable galactosemic cataract model for rats. Int J Clin Exp Med 8(8): 12874-12881, 2015. PMID: 26550203.

22 da Silva-Santi LG, Antunes MM, Caparroz-Assef SM, Carbonera F, Masi LN, Curi R, Visentainer JV and Bazotte RB: Liver fatty acid composition and inflammation in mice fed with high-carbohydrate diet or high-fat diet. Nutrients 8(11): 682, 2016. PMID: 27801862. DOI: $10.3390 /$ nu 8110682

$23 \mathrm{Na}$ HK and Surh YJ: Oncogenic potential of Nrf2 and its principal target protein heme oxygenase-1. Free Radic Biol Med 67: 353-365, 2014. PMID: 24200599. DOI: 10.1016/ j.freeradbiomed.2013.10.819
24 Zhang J, Shi X, Chen Z, Geng J, Wang Y, Feng H, Zhu G and Chen Q: Edaravone reduces iron-mediated hydrocephalus and behavioral disorder in rat by activating the $\mathrm{Nrf} 2 / \mathrm{HO}-1$ pathway. J Stroke Cerebrovasc Dis 27(12): 3511-3520, 2018. PMID: 30205995. DOI: 10.1016/j.jstrokecerebrovasdis.2018.08.019

25 Keum YS, Owuor ED, Kim BR, Hu R and Kong AN: Involvement of Nrf2 and JNK1 in the activation of antioxidant responsive element (ARE) by chemopreventive agent phenethyl isothiocyanate (PEITC). Pharm Res 20(9): 1351-1356, 2003. PMID: 14567627. DOI: 10.1023/a:1025737622815

26 Owusu BY, Stapley R, Honavar J and Patel RP: Effects of erythrocyte aging on nitric oxide and nitrite metabolism. Antioxid Redox Signal 19(11): 1198-1208, 2013. PMID: 23311696. DOI: 10.1089 /ars.2012.4884

27 Hyogo $\mathrm{H}$ and Yamagishi S: Advanced glycation end products (AGEs) and their involvement in liver disease. Curr Pharm Des 14(10): 969-972, 2008. PMID: 18473847. DOI: 10.2174/ 138161208784139701

28 Park JH, Park B and Park KK: Suppression of hepatic epithelialto-mesenchymal transition by melittin via blocking of TGF $/$ /Smad and MAPK-JNK signaling pathways. Toxins (Basel) 9(4): 138, 2017. PMID: 28406452. DOI: 10.3390/ toxins 9040138

29 Liangpunsakul S, Haber P and McCaughan GW: Alcoholic liver disease in Asia, Europe, and North America. Gastroenterology 150(8): 1786-1797, 2016. PMID: 26924091. DOI: 10.1053/ j.gastro.2016.02.043
Received March 17, 2021

Revised April 15, 2021

Accepted April 22, 2021 